\title{
Hydrothermal Synthesis of 1T-MoS $/$ /Pelagic Clay Composite and Its Application in the Catalytic Reduction of 4-Nitrophenol
}

\author{
Nan $\mathrm{Li}^{1}{ }^{1}$, Qiwei Sun ${ }^{1}$, Peiping Zhang ${ }^{1}$ and Shubo Jing ${ }^{2, *(\mathbb{D}}$ \\ 1 Key Laboratory of Automobile Materials of Ministry of Education, School of Material Science and \\ Engineering, Jilin University, 5988 Renmin Street, Changchun 130022, China; lin@jlu.edu.cn (N.L.); \\ sunqw0802@163.com (Q.S.); zhangpp@jlu.edu.cn (P.Z.) \\ 2 College of Chemistry, Jilin University, 2699 Qianjin Street, Changchun 130012, China \\ * Correspondence: jingsb@jlu.edu.cn
}

Citation: Li, N.; Sun, Q.; Zhang, P.; Jing, S. Hydrothermal Synthesis of $1 \mathrm{~T}-\mathrm{MoS}_{2} /$ Pelagic Clay Composite and Its Application in the Catalytic Reduction of 4-Nitrophenol. Materials 2021, 14, 7020. https://doi.org/ $10.3390 / \mathrm{ma} 14227020$

Academic Editors: Ivan Shtepliuk and Filippo Giannazzo

Received: 27 October 2021

Accepted: 16 November 2021

Published: 19 November 2021

Publisher's Note: MDPI stays neutral with regard to jurisdictional claims in published maps and institutional affiliations.

Copyright: (c) 2021 by the authors. Licensee MDPI, Basel, Switzerland. This article is an open access article distributed under the terms and conditions of the Creative Commons Attribution (CC BY) license (https:/ / creativecommons.org/licenses/by/ $4.0 /)$.

\begin{abstract}
Pelagic clay is an emerging marine resource with strong hydrophilicity, fine particles and a large specific surface area. In this work, a $1 \mathrm{~T}-\mathrm{MoS}_{2} /$ pelagic clay composite was fabricated by hydrothermal synthesis. In the composite, $1 \mathrm{~T}-\mathrm{MoS}_{2}$ nanosheets are evenly dispersed on the surface of the clay minerals, significantly reducing the agglomeration of $\mathrm{MoS}_{2}$. Compared with pure 1T-MoS the $1 \mathrm{~T}-\mathrm{MoS}_{2}$ nanosheets generated on the surface of pelagic clay have significantly smaller lateral dimensions and thicknesses. Moreover, the specific surface area is much larger than that of the pure $1 \mathrm{~T}-\mathrm{MoS}_{2}$ nanosheets fabricated by the same method, indicating that the active sites of the $\mathrm{MoS}_{2}$ sheets are fully exposed. In addition, the composite exhibited excellent hydrophilicity, leading to a high dispersibility in aqueous solutions. In this work, the composite was used as a catalyst in the reduction of 4-nitrophenol (4-NP), and the conversion of 4-NP reached up to $96.7 \%$. This result shows that the $1 \mathrm{~T}-\mathrm{MoS}_{2}$ / pelagic clay composite is a promising catalyst in a variety of reactions.
\end{abstract}

Keywords: molybdenum disulfide; pelagic clay; catalytic reduction; 4-nitrophenol

\section{Introduction}

4-nitrophenol(4-NP) is one of the most prevalent organic pollutants in wastewater resulted from agricultural and industrial sources [1-4]. Various methods have been applied for the removal of 4-NP pollutants from the environment, mainly including adsorption, microbial degradation, electrochemical treatment and catalytic reduction [5-9]. Direct catalytic reduction of 4-NP to 4-aminophenol (4-AP) is one of the most effective, environmentally friendly and economical methods for 4-NP removal. 4-AP is a very important intermediate for many industrial products, such as paracetamol, painkillers and dyes [10,11]. Compared to the high-temperature and high-pressure gas-phase hydrogenation process with $\mathrm{H}_{2}$ as the hydrogen source that involves tedious operations, the liquid-phase reduction process with sodium borohydride $\left(\mathrm{NaBH}_{4}\right)$ as the hydrogen source is more desirable and has been widely investigated due to its mild reaction conditions and simple operation [12,13]. However, 4-NP and $\mathrm{NaBH}_{4}$ hardly react in the absence of a catalyst because of unfavorable kinetics. Therefore, an efficient catalyst is necessary for this reaction. The most reported catalysts for the reduction of 4-NP to 4-AP are noble metals such as Au, Ag, Pt and Pd [14-16]. Unfortunately, the practical application of these catalysts is limited by the high cost and scarcity. Accordingly, the search for efficient and cost-effective alternative catalysts is essential and critical for environmental protection [17-20].

As a typical Two-dimensional (2D) layered transition metal disulfide, $\mathrm{MoS}_{2}$ is considered to be a promising catalyst for replacing noble metals because its edge sites exhibit catalytic activity similar to platinum [21]. $\mathrm{MoS}_{2}$ is usually found in the semiconducting $2 \mathrm{H}$ phase (trigonal prismatic coordination) in nature. However, the metallic $1 \mathrm{~T}$ phase (octahedral coordination) of $\mathrm{MoS}_{2}\left(1 \mathrm{~T}-\mathrm{MoS}_{2}\right)$ is of higher electrical conductivity and more catalytic active sites; therefore, it has shown excellent catalytic activity in electrocatalytic 
reactions [22,23]. In recent years, hydrothermal methods have been developed to fabricate $1 \mathrm{~T}-\mathrm{MoS}_{2}$ except for the traditional exfoliation strategy with lithium ions [24]. However, pure $1 \mathrm{~T}-\mathrm{MoS}_{2}$ nanosheets prepared by hydrothermal methods are prone to agglomerate to form nanospheres, leading to blockage of the active sites and decline in catalytic activity $[25,26]$. It has been reported that growing $1 \mathrm{~T}-\mathrm{MoS}_{2}$ nanosheets on a substrate like graphene can effectively inhibit the aggregation, improve the dispersion and stability of $1 \mathrm{~T}-\mathrm{MoS}_{2}[27,28]$. In our previous study, a symbiotic composite of $1 \mathrm{~T}-\mathrm{MoS}_{2}$ and pelagic clay was synthesized by a facile hydrothermal method, and the composite exhibited excellent catalytic activity in the photocatalytic degradation of tetracycline hydrochloride [29].

Pelagic clay is a deep-sea sedimentary clay mineral containing montmorillonite, illite and kaolinite. As an emerging marine resource, pelagic clay has many advantages, such as extremely rich reserves, high hydrophilicity, fine particles, high structural activity and large specific surface area [30].

In this work, a composite of $1 \mathrm{~T}-\mathrm{MoS}_{2}$ with pelagic clays was fabricated by a simple hydrothermal method. 1T-MoS 2 in the composite accounts for approximately was $57.9 \%$. Moreover, the $\mathrm{MoS}_{2}$ nanosheets are relatively uniformly dispersed on the clay minerals surface, which inhibits the agglomeration of the $\mathrm{MoS}_{2}$ nanosheets, increases the specific surface area by approximately six times and enhances the exposed catalytic active sites. The composite also exhibits excellent hydrophilicity, which enables a better dispersion in aqueous solution. When it was used in the catalytic reduction of 4-NP, the conversion of 4-NP reached $96.7 \%$.

\section{Materials and Methods}

\subsection{Materials}

Pelagic clay was got from the bottom of the Indian Ocean. Prior to the synthesis, the pelagic clay was thoroughly washed with deionized water, filtered, dried at $80{ }^{\circ} \mathrm{C}$ for $24 \mathrm{~h}$ and then ground manually with an agate mortar until there was no obvious grainy substance. All of the chemicals were analytical grade reagents. Hexadecyl trimethyl ammonium bromide $(\mathrm{CTAB})$, sodium molybdate $\left(\mathrm{Na}_{2} \mathrm{MoO}_{4} \cdot 2 \mathrm{H}_{2} \mathrm{O}\right)$, thiourea $\left(\left(\mathrm{NH}_{2}\right)_{2} \mathrm{CS}\right)$, 4-nitrophenol (4-NP), sodium borohydride $\left(\mathrm{NaBH}_{4}\right)$ and propionic acid were purchased from Chemical Reagent Factory (Beijing, China).

\subsection{Fabrication of $1 \mathrm{~T}-\mathrm{MoS}_{2} / \mathrm{PC}$ Composites}

Firstly, $1.2 \mathrm{~g}$ pelagic clay was dispersed into the mixture of $0.14 \mathrm{~g}$ hexadecyl trimethyl ammonium bromide (CTAB) and $20 \mathrm{~mL}$ of deionized water, and then stirred at $60{ }^{\circ} \mathrm{C}$ for $24 \mathrm{~h}$. Subsequently, $0.484 \mathrm{~g}$ sodium molybdate $\left(\mathrm{Na}_{2} \mathrm{MoO}_{4} \cdot 2 \mathrm{H}_{2} \mathrm{O}\right), 0.76 \mathrm{~g}$ thiourea $\left(\left(\mathrm{NH}_{2}\right)_{2} \mathrm{CS}\right)$ and $16 \mathrm{~mL}$ propionic acid were added into the above solution. Finally, the whole mixture was transferred into a $100 \mathrm{~mL}$ Teflon-lined stainless-steel autoclave and kept at $180{ }^{\circ} \mathrm{C}$ for $4 \mathrm{~h}$. After the reaction, the precipitate was centrifuged and washed with deionized water and ethanol three times and dried in a vacuum oven for $24 \mathrm{~h}$. The product was marked as 1T-MoS $2 / \mathrm{PC}$. The content of $\mathrm{MoS}_{2}$ in the 1T-MoS $/ \mathrm{PC}$ composite was estimated to be $\sim 20 \%$ (wt.\%) according to the ratio between the theoretical yield of $\mathrm{MoS}_{2}$ and the feeding quality of pelagic clay. For comparison, a pure $\mathrm{MoS}_{2}$ sample without pelagic clay was also prepared through a similar process. The product was marked as $1 \mathrm{~T}-\mathrm{MoS}_{2}$.

\subsection{Material Characterization}

Powder X-ray diffraction (PXRD) (Fangyuan Instrument Co., Ltd., Dandong, China) was tested on a DX2700 diffractometer with a $\mathrm{Cu} \mathrm{K} \alpha$ radiation source $(\lambda=1.5406 \mathrm{~nm})$, with a measurement in $2 \theta$ range: $5^{\circ}$ to $80^{\circ}$. Scanning electron microscopy (SEM) (Electronics Co., Ltd., Tokyo, Japan) analysis was accomplished on a JEOL JSM-6700F microscope. Transmission electron microscopy (TEM) (Electronics Co., Ltd., Japan) and energy dispersive spectroscopy (EDS) (Electronics Co., Ltd., Japan) characterization were performed on a JEOL JEM-2100F microscope at $200 \mathrm{kV}$. X-ray photoelectron spectroscopy (XPS) (Ther- 
moFisher, Waltham, MA, USA) analysis was performed on an EscaLab 250Xi electronic spectrometer. Raman spectra were measured using a micro-Raman spectrometer (Renishaw, Wotton-under-Edge, UK) with a laser wavelength of $532 \mathrm{~nm}$ at $0.2 \mathrm{~mW}$. A C20001C contact angle meter (Zhongchen Digital Technology Equipment Co., Ltd., Shanghai, China) was used to characterize the surface wettability of samples. UV-vis spectra were recorded in the range of 250-550 nm on a T6-NC (Persee, Beijing, China) spectrophotometer. A JWBK222 (jingweigaobo, Beijing, China) automated sorption system was used for nitrogen adsorption-desorption measurement. Specific surface area data were obtained by the Brunauer-Emmet-Teller (BET) method.

\subsection{Catalytic Activity Evaluation}

The reduction of 4-NP to 4-AP was conducted in water in the presence of $1 \mathrm{~T}-\mathrm{MoS}_{2} / \mathrm{PC}$ using $\mathrm{NaBH}_{4}$ as the reductant. The catalytic activity of $1 \mathrm{~T}-\mathrm{MoS}_{2} / \mathrm{PC}$ was evaluated by measuring the conversion of 4-NP.

In a typical catalytic reduction reaction, $0.136 \mathrm{~g}$ (excess) of sodium borohydride $\left(\mathrm{NaBH}_{4}\right)$ was added to $50 \mathrm{~mL}$ of $0.12 \mathrm{mmol} / \mathrm{L} 4-\mathrm{NP}$ solution and stirred until $\mathrm{NaBH}_{4}$ was completely dissolved. Subsequently, $1 \mathrm{~T}-\mathrm{MoS}_{2} / \mathrm{PC}$ catalyst (with various solid-liquid ratio of $1-6 \mathrm{~g} / \mathrm{L}$ ) was added into the above solution. The mixture was magnetically stirred at various temperatures $\left(20-50{ }^{\circ} \mathrm{C}\right)$ for $15 \mathrm{~min}$. After the reaction, the mixture was separated by filtration. The catalyst powder was recovered, and one milliliter of filtrate was poured into a quartz cell for UV-vis spectroscopy analysis.

4-NP shows a characteristic peak at $400 \mathrm{~nm}$ wavenumber in the UV-vis spectrum, and the intensity of the absorption peak is linearly connected with the concentration of 4-NP. Consequently, the conversion of 4-NP was calculated by measuring the absorbance of the solution at $400 \mathrm{~nm}$ before and after the reaction $[1,14,31]$. The absorptions with various concentrations of 4-NP were measured (from $0.0024 \mathrm{mmol} / \mathrm{L}$ to $0.12 \mathrm{mmol} / \mathrm{L}$ ), and the linear standard equation is fitted with: $\mathrm{y}=0.00217+17.00795 \mathrm{x}$ (where $\mathrm{y}$ represents absorbance and $x$ represents concentration of $4-\mathrm{NP}$ in $\mathrm{mmol} / \mathrm{L}$ ). The conversions of 4-NP $(\mathrm{C}(\%))$ was calculated according to the following formula: $\mathrm{C}(\%)=\left(\left(\mathrm{C}_{0}-\mathrm{C}_{1}\right) / \mathrm{C}_{0}\right) \times 100 \%$, where $\mathrm{C}_{0}$ and $\mathrm{C}_{1}$ is the concentration of 4 -NP before and after the reaction, respectively.

\section{Results and Discussion}

\subsection{Structural Characterization}

The crystallographic structures of pelagic clay, pure $1 \mathrm{~T}-\mathrm{MoS}_{2}$ and $1 \mathrm{~T}-\mathrm{MoS}_{2} / \mathrm{PC}$ were characterized utilizing X-ray diffraction (XRD) measurements. As shown in Figure 1, the XRD pattern of pelagic clay reveals its poor crystallization. Only diffraction peaks from impurities (e.g., quartz, feldspar, kaolinite, calcite) are observed [29]. The XRD pattern of pure 1T-MoS 2 clearly displays three typical diffraction peaks that correspond to the (002), (100) and (110) planes of $\mathrm{MoS}_{2}$, respectively. For 1T-MoS $/$ /PC, the characteristic peaks of pelagic clay and two weak diffraction peaks representing the (100) and (110) planes of $1 \mathrm{~T}-\mathrm{MoS}_{2}$ can be observed. However, the peak of (002) crystal plane on the $1 \mathrm{~T}-\mathrm{MoS}_{2}$ is much weaker and almost invisible, indicating that fewer layers of $\mathrm{MoS}_{2}$ nanosheets are stacked along the c-axis [1]. The XRD analysis reveals that the presence of pelagic clay reduces the long-range ordering of $1 \mathrm{~T}-\mathrm{MoS}_{2}$ crystals. 


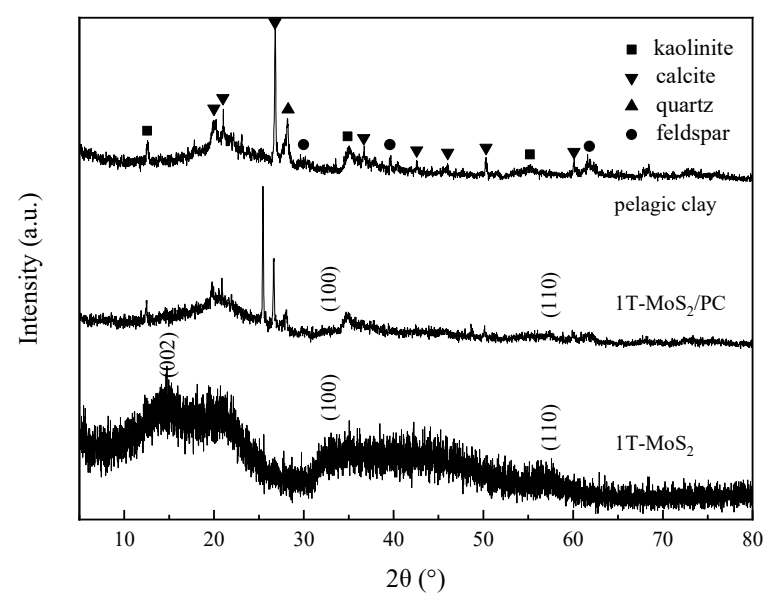

Figure 1. XRD patterns of pelagic clay, $1 \mathrm{~T}-\mathrm{MoS}_{2}$ and $1 \mathrm{~T}-\mathrm{MoS}_{2} / \mathrm{PC}$.

To support this hypothesis, we analyzed the microscopic morphology of pure 1T-MoS 2 and the 1T-MoS 2 / PC composite. The SEM images of 1T-MoS 2 and 1T-MoS 2 / PC samples are presented in Figure 2. Pure 1T-MoS 2 exhibits obvious agglomeration of nanosheets, performing a flower-like structure with a diameter of $\sim 500 \mathrm{~nm}$ (Figure 2a). The lateral size of each $\mathrm{MoS}_{2}$ nanosheet is approximately 200-300 nm. In contrast, in the $1 \mathrm{~T}-\mathrm{MoS}_{2} / \mathrm{PC}$ composite (Figure 2b), the agglomeration of $\mathrm{MoS}_{2}$ nanosheets is almost entirely absent. The $\mathrm{MoS}_{2}$ nanosheets in the composite disperse relatively uniformly on the pelagic clay mineral surface. Compared to pure $1 \mathrm{~T}-\mathrm{MoS}_{2}$, the lateral size of the $\mathrm{MoS}_{2}$ nanosheets is significantly smaller $(\sim 100-200 \mathrm{~nm})$, and their thickness is reduced from $\sim 24 \mathrm{~nm}$ to $\sim 11.9 \mathrm{~nm}$, which agrees well with the XRD results. The size reduction of the $\mathrm{MoS}_{2}$ nanosheets provides more edges and significantly increases exposed active sites.
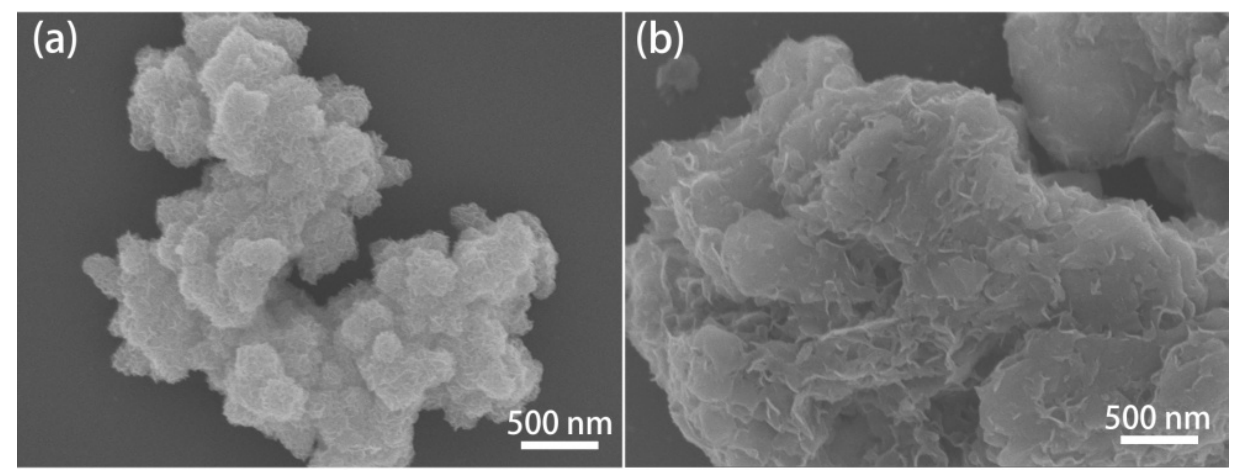

Figure 2. SEM images of (a) $1 \mathrm{~T}-\mathrm{MoS}_{2}$ and (b) $1 \mathrm{~T}-\mathrm{MoS}_{2} / \mathrm{PC}$.

TEM and high-resolution transmission electron microscopy (HRTEM) images of the $1 \mathrm{~T}-\mathrm{MoS}_{2} / \mathrm{PC}$ are shown in Figure 3. The sample has a typical layered structure. The dark areas (Figure 3a) are composed of thick pelagic clay layers, while the flocculent substance with small contrast is a thinner $\mathrm{MoS}_{2}$ sheet. A well-stacked layered structure with a lattice spacing of $0.62 \mathrm{~nm}$ is evidently visualized in Figure 3b, corresponding to the (002) crystal plane of $1 \mathrm{~T}-\mathrm{MoS}_{2}$. This is solid evidence for the presence of $\mathrm{MoS}_{2}$ [1]. Energy dispersive spectroscopy (EDS) confirmed this result. As displayed in Figure $3 c-f$, the thicker areas of the sample contain mainly $\mathrm{Si}$ and $\mathrm{Al}$, which are the major components of the pelagic clay minerals. The surrounding flocculent substance contains mainly $S$ and Mo, suggesting that these areas are mainly $\mathrm{MoS}_{2}$. This result also proves the composite structure of $\mathrm{MoS}_{2}$ and pelagic clay. 

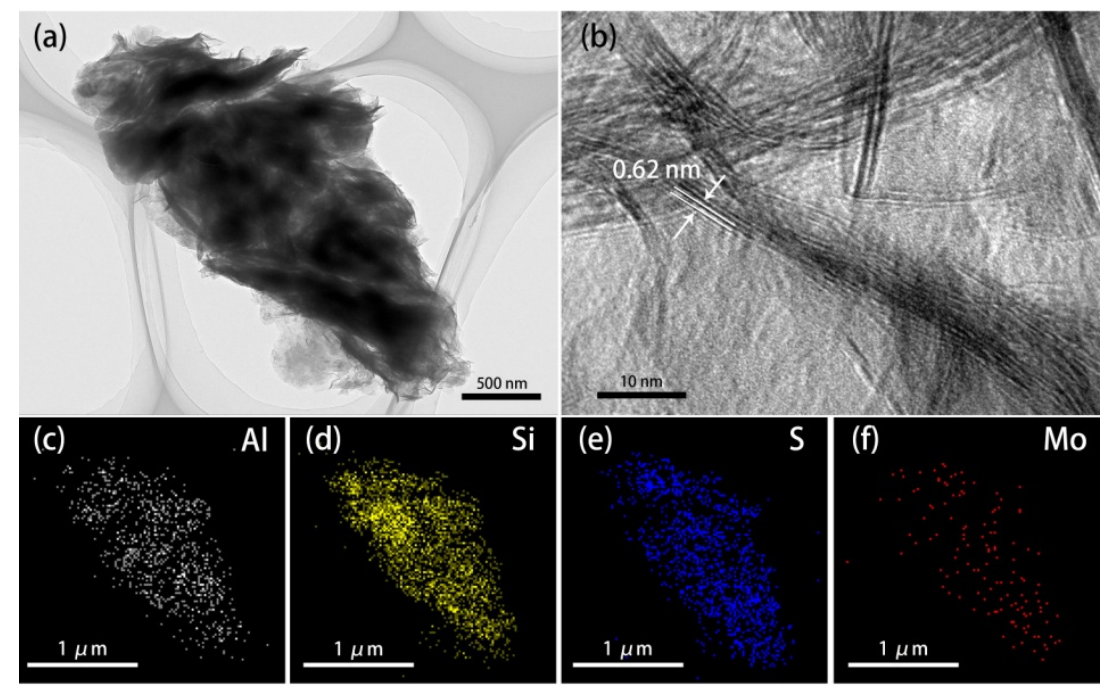

Figure 3. (a) TEM image and (b) HRTEM image of $1 \mathrm{~T}-\mathrm{MoS}_{2} / \mathrm{PC}$, and (c-f) element distribution of $\mathrm{Al}$, $\mathrm{Si}, \mathrm{S}$ and $\mathrm{Mo}$ in $1 \mathrm{~T}-\mathrm{MoS}_{2} / \mathrm{PC}$.

To further investigate the surface elemental composition and the chemical feature, XPS measurements were conducted on 1T- $\mathrm{MoS}_{2}$ and $1 \mathrm{~T}-\mathrm{MoS}_{2} / \mathrm{PC}$ samples under a survey scan that was performed in the range of $0-700 \mathrm{eV}$. As exhibited in Figure $4 \mathrm{a}, \mathrm{Al}, \mathrm{Si}$, S and Mo peaks are observed in the XPS spectrum of $1 \mathrm{~T}-\mathrm{MoS}_{2} / \mathrm{PC}$. The binding energies of the Mo 3d electrons for both 1T-MoS 2 and $1 \mathrm{~T}-\mathrm{MoS}_{2} / \mathrm{PC}$ can be fitted to two pairs of peaks (Figure $4 \mathrm{~b}$ ). The doublet with the higher binding energy is attributed to Mo $3 d_{5 / 2}$ and $3 d_{3 / 2}$ orbitals in the $2 \mathrm{H}$ phase $\mathrm{MoS}_{2}$, indicating that these two samples contain a small amount of the $2 \mathrm{H}$ phase $[32,33]$. This phase is present because the $1 \mathrm{~T}$ phase is thermodynamically unstable and part of it undergoes a transformation to the more stable $2 \mathrm{H}$ phase. These two peaks are located at 229.5 and $232.9 \mathrm{eV}$ for $1 \mathrm{~T}-\mathrm{MoS}_{2} / \mathrm{PC}$ and are located at 229.8 and $233.2 \mathrm{eV}$ for $1 \mathrm{~T}-\mathrm{MoS}_{2}$, in agreement with the literature data [23]. The pair of peaks with lower binding energies in the spectrum then corresponds to Mo $3 d_{5 / 2}$ and $3 d_{3 / 2}$ in the $1 T$ phase $\mathrm{MoS}_{2}$. These two peaks lie in at 228.9 and $232.1 \mathrm{eV}$ on 1T-MoS $2 / \mathrm{PC}$ and at 229.1 and $232.3 \mathrm{eV}$ on $1 \mathrm{~T} \mathrm{MoS}$, respectively. The binding energies were $0.6-0.8 \mathrm{eV}$ lower than that of the corresponding $2 \mathrm{H}$ phase $\mathrm{MoS}_{2}$, demonstrating that $1 \mathrm{~T}$ phase $\mathrm{MoS}_{2}$ was present in the $1 \mathrm{~T}-\mathrm{MoS}_{2} /$ pelagic clay composite. The difference existed in the binding energies was due to the different coordination structures of the $1 \mathrm{~T}$ and $2 \mathrm{H}$ phases [31].

The high-resolution spectra of $S 2 p$ (Figure $4 c$ ) indicates that the $S 2 p_{3 / 2}$ and $S 2 p_{1 / 2}$ signals of $1 \mathrm{~T}-\mathrm{MoS}_{2} / \mathrm{PC}$ are located at 161.8 and $163.2 \mathrm{eV}$, respectively, lower than the binding energies of $S 2 p_{3 / 2}$ and $S 2 p_{1 / 2}$ in $1 T M_{2}$ (162.0 and $163.6 \mathrm{eV}$ ). Based on the above results, it is concluded that electron transport from the pelagic clay to $1 \mathrm{~T}-\mathrm{MoS}_{2}$ occurred [1,34], proving that the $\mathrm{MoS}_{2}$ orbitals are tightly hybridized with those of pelagic clay in the 1T- $\mathrm{MoS}_{2} / \mathrm{PC}$ composite. According to the ratio of the Mo $3 \mathrm{~d}$ peak area in the XPS spectrum, the $1 \mathrm{~T}$ phase content in 1T-MoS 2 was $46.2 \%$, and the $1 \mathrm{~T}$ phase content in the $1 \mathrm{~T}-\mathrm{MoS}_{2} / \mathrm{PC}$ composite was $57.9 \%$. 

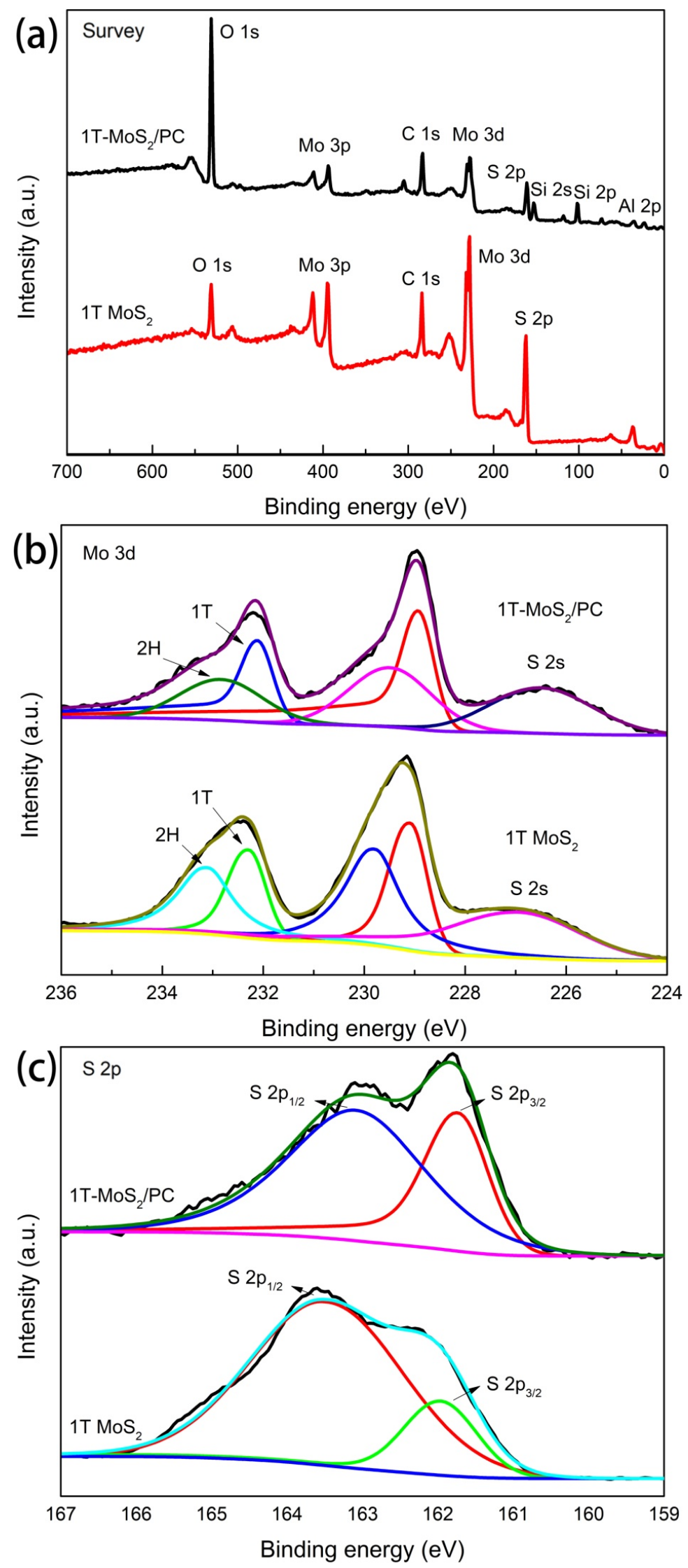

Figure 4. (a) XP survey spectra of $1 \mathrm{~T}-\mathrm{MoS}_{2} / \mathrm{PC}$ and $1 \mathrm{~T}-\mathrm{MoS}_{2}$. High-resolution scans for (b) Mo 3d and (c) $S 2 p$. 
To further verify that the $\mathrm{MoS}_{2}$ in the $1 \mathrm{~T}-\mathrm{MoS}_{2} / \mathrm{PC}$ is found predominantly in the $1 \mathrm{~T}$ phase, Raman spectroscopy was employed to determine the phase structure of the samples (Figure 5). In addition to the two characteristic peaks located at 385 and $404 \mathrm{~cm}^{-1}$ corresponding to the in-plane and interlayer vibrations of $2 \mathrm{H}$-phase $\mathrm{MoS}_{2}$, there are two peaks at 235 and $336 \mathrm{~cm}^{-1}$, which correspond to the $\mathrm{J}_{2}$ and $\mathrm{J}_{3}$ vibrational peaks of the 1T-phase $\mathrm{MoS}_{2}$, respectively. This result provides strong evidence that 1T-phase $\mathrm{MoS}_{2}$ exists in the $1 \mathrm{~T}-\mathrm{MoS}_{2} / \mathrm{PC}$ composite.

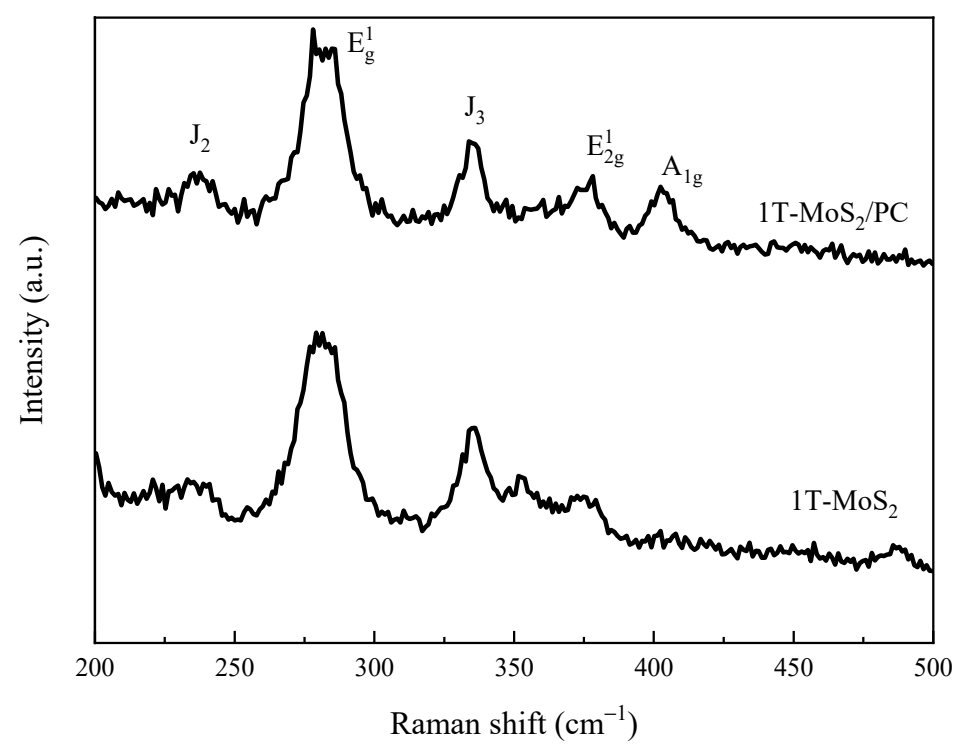

Figure 5. Raman spectra of $1 \mathrm{~T}-\mathrm{MoS}_{2} / \mathrm{PC}$ and $1 \mathrm{~T}-\mathrm{MoS}_{2}$.

Figure 6 presents the results of the surface wettability. Pure 1T-MoS 2 exhibits hydrophobicity with a $112.4^{\circ}$ water contact angle. In contrast, the contact angle decreased drastically to $34.3^{\circ}$ after the sample was hybridized by pelagic clay, suggesting that the pelagic clay significantly enhanced the hydrophilicity of the $1 \mathrm{~T} \mathrm{MoS}$. This increased hydrophilicity not only improves the dispersion of $\mathrm{MoS}_{2}$ in aqueous solutions, but benefits its application as a catalyst in aqueous media.
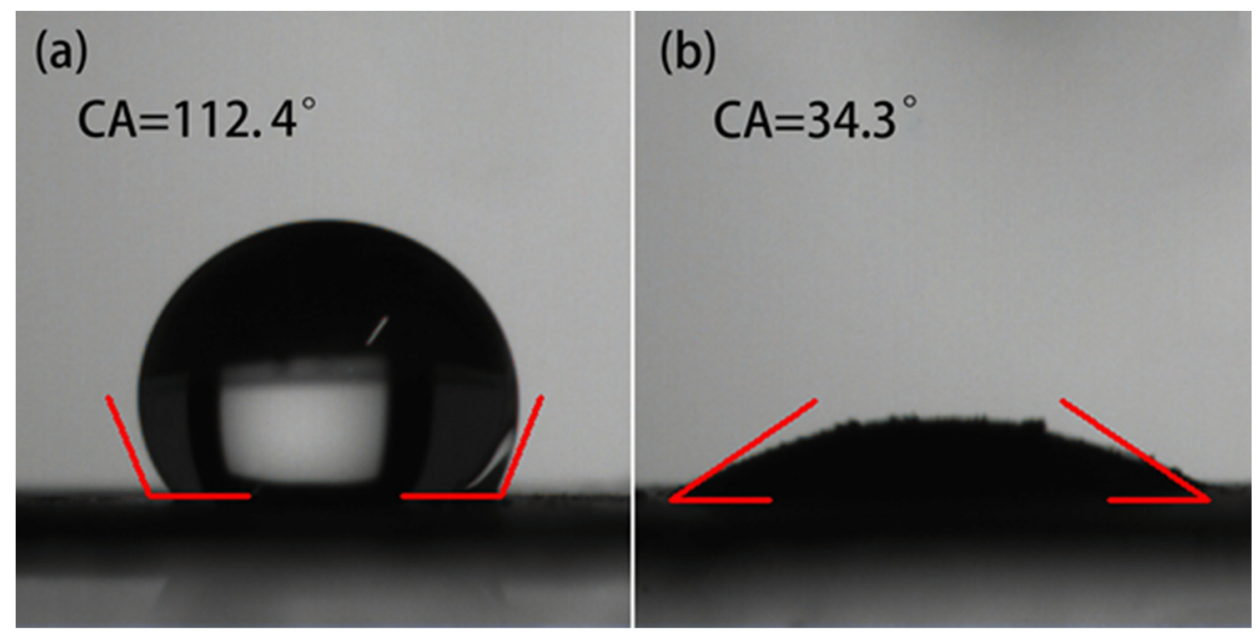

Figure 6. Surface wettability of (a) $1 \mathrm{~T}-\mathrm{MoS}_{2}$ and (b) $1 \mathrm{~T}-\mathrm{MoS}_{2} / \mathrm{PC}$.

Additionally, the BET surface areas of the $1 \mathrm{~T}-\mathrm{MoS}_{2}, 1 \mathrm{~T}-\mathrm{MoS}_{2} / \mathrm{PC}$ and pelagic clay were measured and were found to be 4.4, 27.0 and $100.4 \mathrm{~m}^{2} \mathrm{~g}^{-1}$, respectively. Based on the analysis of these data, following its hybridization with pelagic clay, $1 \mathrm{~T}-\mathrm{MoS}_{2} / \mathrm{PC}$ exhibited 
a 6-fold increase in the BET surface area in contrast with that of pure 1T-MoS 2 , further demonstrating its potential to be an efficient catalyst.

\subsection{Testing of the Catalytic Behavior of $1 \mathrm{~T}-\mathrm{MoS}_{2} / \mathrm{PC}$}

We determined the catalytic activity of the samples in reduction reaction in the aqueous phase and with $\mathrm{NaBH}_{4}$ as the reductant at $30^{\circ} \mathrm{C}$. The absorbance at $400 \mathrm{~nm}$ in the UV-visible spectrum was measured and converted to the concentration of 4-NP. The experimental results suggest that pure pelagic clay was inert in the reduction of 4-NP (Figure 7). Pure $1 \mathrm{~T}-\mathrm{MoS}_{2}$ was catalytically active for the reaction (88.5\% conversion of 4-NP). When $\mathrm{MoS}_{2}$ was hybridized with pelagic clay, its catalytic reduction activity was significantly enhanced. The conversion of $4-\mathrm{NP}$ was as high as $96.9 \%$ within $15 \mathrm{~min}$ at $30{ }^{\circ} \mathrm{C}$ when the $1 \mathrm{~T}-\mathrm{MoS}_{2} / \mathrm{PC}$ composite was used as the catalyst.

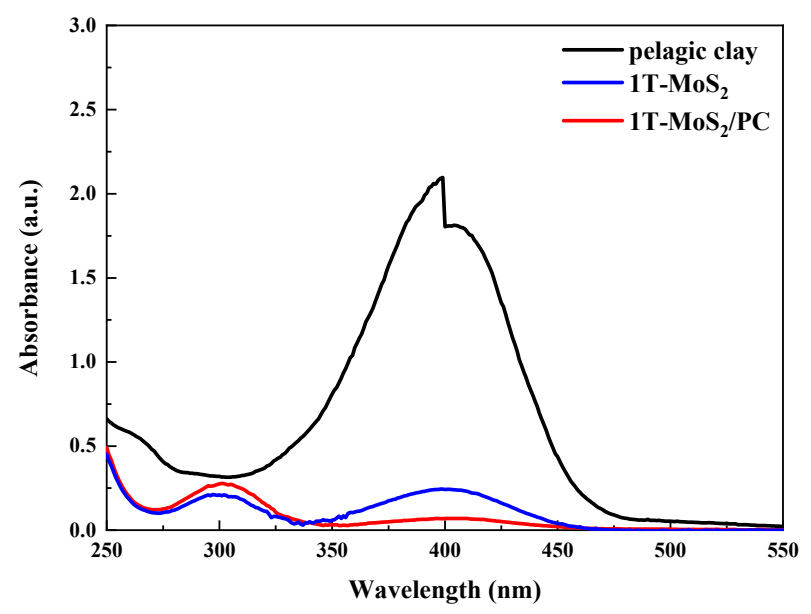

Figure 7. UV-vis absorption spectra of catalytic reduction of 4-NP with $\mathrm{NaBH}_{4}$ over pelagic clay, $1 \mathrm{~T}-\mathrm{MoS}_{2}$ and $1 \mathrm{~T}-\mathrm{MoS}_{2} / \mathrm{PC}$ at a solid/liquid ratio of $3 \mathrm{~g} / \mathrm{L}$. (The initial concentration of $4-\mathrm{NP}$ was $0.12 \mathrm{mmol} / \mathrm{L})$.

To further investigate the influence of the mass content of $1 \mathrm{~T}-\mathrm{MoS}_{2} / \mathrm{PC}$ on the conversion of 4-NP, various quality of $1 \mathrm{~T}-\mathrm{MoS}_{2} / \mathrm{PC}$ were added to the solution containing 4-NP and $\mathrm{NaBH}_{4}$ to reach a solid/liquid ratio of 1, 2, 3, 4, 5 and $6 \mathrm{~g} / \mathrm{L}$. The results are shown in Figure 8. The conversion of 4-NP corresponding to the six different content of catalysts is $63.2 \%, 82.2 \%, 96.9 \%, 97.7 \%, 99.8 \%$ and $99.9 \%$, respectively (Figure 9 ). When the quality of the added catalyst was small, the conversion of 4-NP increased significantly with increasing catalyst quality. After the solid/liquid ratio reached $3 \mathrm{~g} / \mathrm{L}, 4-\mathrm{NP}$ conversions reached more than $95 \%$ within $15 \mathrm{~min}$. Then, the catalyst quality continued to increase, and the conversions of the 4-NP increase were not significant. Therefore, a solid/liquid ratio of $3 \mathrm{~g} / \mathrm{L}$ is the optimal catalyst addition quality in terms of cost. 


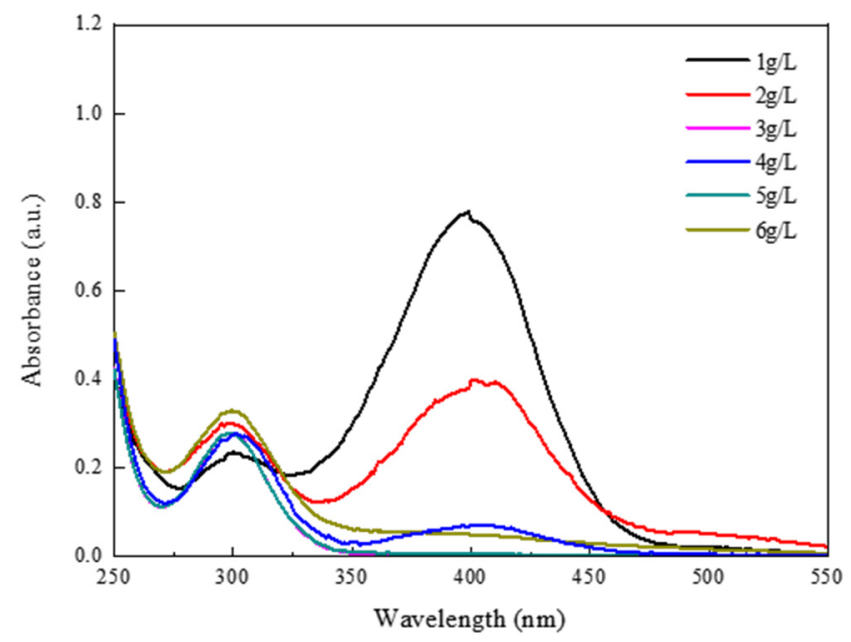

Figure 8. UV-vis absorption spectra of the 4-NP solution with various quality of $1 \mathrm{~T}-\mathrm{MoS}_{2} / \mathrm{PC}$. (The initial concentration of 4-NP was $0.12 \mathrm{mmol} / \mathrm{L}$ ).

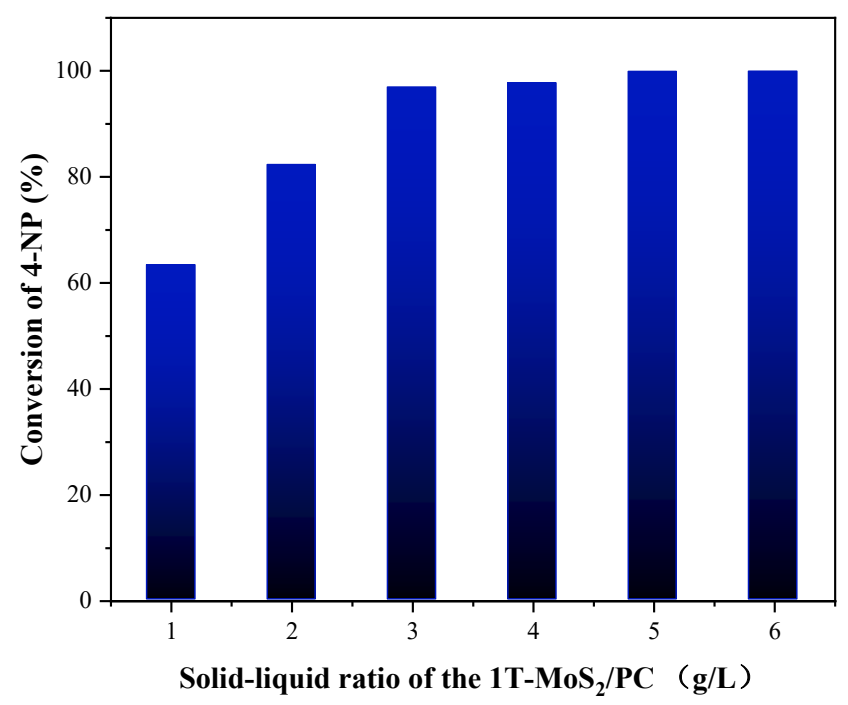

Figure 9. Influence of the $1 \mathrm{~T}-\mathrm{MoS}_{2} / \mathrm{PC}$ content on the catalytic reduction of 4-NP.

The effect of the temperature on the conversion of 4-NP was also investigated. The catalytic reduction activity of $1 \mathrm{~T}-\mathrm{MoS}_{2} / \mathrm{PC}$ was measured at a solid/liquid ratio of $3 \mathrm{~g} / \mathrm{L}$ for $15 \mathrm{~min}$ at $20-50{ }^{\circ} \mathrm{C}$, and the experimental results are shown in Figure 10 . The conversion of $4-\mathrm{NP}$ is $88.2 \%, 96.9 \%, 98.5 \%$ and $99.4 \%$ at $20{ }^{\circ} \mathrm{C}, 30{ }^{\circ} \mathrm{C}, 40{ }^{\circ} \mathrm{C}$ and $50{ }^{\circ} \mathrm{C}$, respectively. The extent of the reaction gradually increased with increasing temperature. At $30^{\circ} \mathrm{C}$, the reaction proceeded up to $96.9 \%$. Further increases in the temperature did not noticeably affect the extent of the reaction. Therefore, $30^{\circ} \mathrm{C}$ is a relatively suitable reaction temperature for this reaction. 


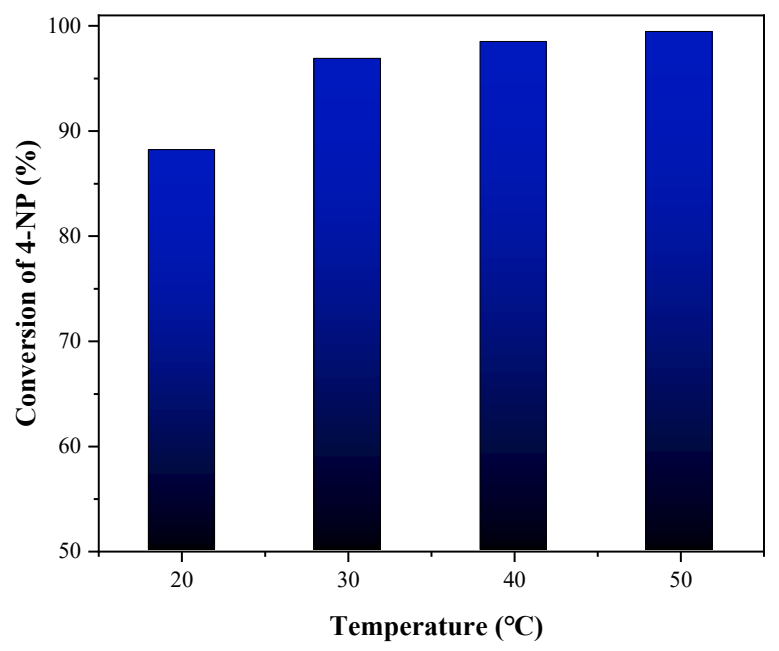

Figure 10. Effect of temperature on catalytic reaction of $1 \mathrm{~T}-\mathrm{MoS}_{2} / \mathrm{PC}$.

\section{Conclusions}

In conclusion, a composite catalyst consisting of $1 \mathrm{~T}-\mathrm{MoS}_{2}$ and pelagic clay (1T$\mathrm{MoS}_{2} / \mathrm{PC}$ ) with high catalyst activity was prepared through a simple hydrothermal method. The lateral size and thickness of the $\mathrm{MoS}_{2}$ nanosheets in the composite were significantly decreased, and the specific surface area was significantly increased relative to pure $\mathrm{MoS}_{2}$ nanosheets. Additionally, the hydrophobicity of $\mathrm{MoS}_{2}$ was effectively improved by the excellent hydrophilicity of the pelagic clay itself, enabling it to be better dispersed in solution and enhancing the catalytic activity of the liquid-phase system. The 1T-MoS $/$ PC composite was used for the catalytic reduction of 4-NP to 4-AP. The results revealed that the conversion of 4-NP was as high as $96.9 \%$ in 15 min under optimal reaction conditions $\left(30^{\circ} \mathrm{C}\right.$, catalyst solid/liquid ratio of $3 \mathrm{~g} / \mathrm{L}$ ). The research in this paper provides a new method for the enhancement of the catalytic reduction activity of $\mathrm{MoS}_{2}$ and suggests opportunities for the high value-adding utilization of pelagic clay.

Author Contributions: Conceptualization, N.L. and S.J.; methodology, N.L. and S.J.; design of analysis, P.Z.; validation, Q.S.; formal analysis, N.L. and S.J.; resources, N.L. and S.J.; data curation, N.L. and S.J.; supervision, N.L. and S.J.; writing—original draft, Q.S. and S.J.; writing-review and editing, N.L.; All authors have read and agreed to the published version of the manuscript.

Funding: The authors are grateful for the financial support from the National Natural Science Foundation of China (21727808, 22072056), China Ocean Mineral Resources R\&D Association (COMRA) Special Foundation (DY135-R2-1-01, DY135-46), Scientific and Technological Project of Jilin Province (20190201015JC).

Institutional Review Board Statement: Not applicable.

Informed Consent Statement: Not applicable.

Data Availability Statement: The data presented in this study are available on request from the corresponding author.

Conflicts of Interest: The authors declare that they have no known competing financial interests or personal relationships that could have appeared to influence the work reported in this paper.

\section{References}

1. Peng, K.; Fu, L.; Yang, H.; Ouyang, J.; Tang, A. Hierarchical $\mathrm{MoS}_{2}$ intercalated clay hybrid nanosheets with enhanced catalytic activity. Nano Res. 2017, 10, 570-583. [CrossRef]

2. Wunder, S.; Polzer, F.; Lu, Y.; Mei, Y.; Ballauff, M. Kinetic Analysis of Catalytic Reduction of 4-Nitrophenol by Metallic Nanoparticles Immobilized in Spherical Polyelectrolyte Brushes. J. Phys. Chem. C 2010, 114, 8814-8820. [CrossRef]

3. Chi, Y.; Tu, J.; Wang, M.; Li, X.; Zhao, Z. One-pot synthesis of ordered mesoporous silver nanoparticle/carbon composites for catalytic reduction of 4-nitrophenol. J. Colloid Interface Sci. 2014, 423, 54-59. [CrossRef] [PubMed] 
4. Shi, Y.; Zhang, X.-L.; Feng, G.; Chen, X.; Lu, Z.-H. Ag-SiO 2 nanocomposites with plum-pudding structure as catalyst for hydrogenation of 4-nitrophenol. Ceram. Int. 2015, 41, 14660-14667. [CrossRef]

5. Cao, S.-W.; Fang, J.; Shahjamali, M.M.; Wang, Z.; Yin, Z.; Yang, Y.; Boey, F.Y.C.; Barber, J.; Loo, S.C.J.; Xue, C. In situ growth of Au nanoparticles on $\mathrm{Fe}_{2} \mathrm{O}_{3}$ nanocrystals for catalytic applications. Crystengcomm 2012, 14, 7229-7235. [CrossRef]

6. $\quad$ Liang, W.; Lu, Y.; Li, N.; Li, H.; Zhu, F. Microwave-assisted synthesis of magnetic surface molecular imprinted polymer for adsorption and solid phase extraction of 4-nitrophenol in wastewater. Microchem. J. 2020, 159, 105316. [CrossRef]

7. Moosavifar, M.; Heidari, S.M.; Fathyunes, L.; Ranjbar, M.; Wang, Y.; Arandiyan, H. Photocatalytic Degradation of Dye Pollutant Over FeTPP/NaY Zeolite Nanocomposite. J. Inorg. Organomet. Polym. Mater. 2020, 30, 1621-1628. [CrossRef]

8. Singh, S.; Kumar, N.; Kumar, M.; Agarwal, A.; Mizaikoff, B. Electrochemical sensing and remediation of 4-nitrophenol using bio-synthesized copper oxide nanoparticles. Chem. Eng. J. 2017, 313, 283-292. [CrossRef]

9. Jiang, X.-H.; Wang, L.-C.; Yu, F.; Nie, Y.-C.; Xing, Q.-J.; Liu, X.; Pei, Y.; Zou, J.-P.; Dai, W.-L. Photodegradation of Organic Pollutants Coupled with Simultaneous Photocatalytic Evolution of Hydrogen Using Quantum-Dot-Modified g- $\mathrm{C}_{3} \mathrm{~N}_{4}$ Catalysts under Visible-Light Irradiation. ACS Sustain. Chem. Eng. 2018, 6, 12695-12705. [CrossRef]

10. Dong, Z.; Le, X.; Li, X.; Zhang, W.; Dong, C.; Ma, J. Silver nanoparticles immobilized on fibrous nano-silica as highly efficient and recyclable heterogeneous catalyst for reduction of 4-nitrophenol and 2-nitroaniline. Appl. Catal. B-Environ. 2014, 158, 129-135. [CrossRef]

11. Xiong, R.; Lu, C.; Wang, Y.; Zhou, Z.; Zhang, X. Nanofibrillated cellulose as the support and reductant for the facile synthesis of $\mathrm{Fe}_{3} \mathrm{O}_{4} / \mathrm{Ag}$ nanocomposites with catalytic and antibacterial activity. J. Mater. Chem. A 2013, 1, 14910-14918. [CrossRef]

12. Raza, W.; Ahmad, K.; Kim, H. Fabrication of defective graphene oxide for efficient hydrogen production and enhanced 4-nitrophenol reduction. Nanotechnology 2021, 32, 495404. [CrossRef]

13. Hunge, Y.M.; Yadav, A.A.; Kang, S.-W.; Kim, H.; Fujishima, A.; Terashima, C. Nanoflakes-like nickel cobaltite as active electrode material for 4-nitro-phenol reduction and supercapacitor applications. J. Hazard. Mater. 2021, 419, 126453. [CrossRef]

14. Akbarzadeh, E.; Bahrami, F.; Gholami, M.R. Au and Pt nanoparticles supported on Ni promoted MoS 2 as efficient catalysts for p-nitrophenol reduction. J. Water Process. Eng. 2020, 34, 101142. [CrossRef]

15. Li, C.; Wang, P.; Tian, Y.; Xu, X.; Hou, H.; Wang, M.; Qi, G.; Jin, Y. Long-Range Plasmon Field and Plasmoelectric Effect on Catalysis Revealed by Shell-Thickness-Tunable Pinhole-Free Au@SiO 2 Core-Shell Nanoparticles: A Case Study of p-Nitrophenol Reduction. ACS Catal. 2017, 7, 5391-5398. [CrossRef]

16. Islam, M.R.; Ferdous, M.; Sujan, M.I.; Mao, X.; Zeng, H.; Azam, M.S. Recyclable Ag-decorated highly carbonaceous magnetic nanocomposites for the removal of organic pollutants. J. Colloid Interface Sci. 2020, 562, 52-62. [CrossRef] [PubMed]

17. Garcia-Dali, S.; Paredes, J.I.; Villar-Rodil, S.; Martinez-Jodar, A.; Martinez-Alonso, A.; Tascon, J.M.D. Molecular Functionalization of 2H-Phase $\mathrm{MoS}_{2}$ Nanosheets via an Electrolytic Route for Enhanced Catalytic Performance. ACS Appl. Mater. Interfaces 2021, 13, 33157-33171. [CrossRef] [PubMed]

18. Li, X.; Zeng, C.; Jiang, J.; Ai, L. Magnetic cobalt nanoparticles embedded in hierarchically porous nitrogen-doped carbon frameworks for highly efficient and well-recyclable catalysis. J. Mater. Chem. A 2016, 4, 7476-7482. [CrossRef]

19. Wu, K.-L.; Wei, X.-W.; Zhou, X.-M.; Wu, D.-H.; Liu, X.-W.; Ye, Y.; Wang, Q. NiCo 2 Alloys: Controllable Synthesis, Magnetic Properties, and Catalytic Applications in Reduction of 4-Nitrophenol. J. Phys. Chem. C 2011, 115, 16268-16274. [CrossRef]

20. Zhuang, Y.-T.; Zhu, T.-T.; Ruan, M.; Yu, Y.-L.; Wang, J.-H. A 2D porous $\mathrm{Fe}_{2} \mathrm{O}_{3}$ /graphitic- $\mathrm{C}_{3} \mathrm{~N}_{4}$ /graphene ternary nanocomposite with multifunctions of catalytic hydrogenation, chromium (VI) adsorption and detoxification. J. Mater. Chem. A 2017, 5, 3447-3455. [CrossRef]

21. Laursen, A.B.; Kegnaes, S.; Dahl, S.; Chorkendorff, I. Molybdenum sulfides-efficient and viable materials for electro-and photoelectrocatalytic hydrogen evolution. Energy Environ. Sci. 2012, 5, 5577-5591. [CrossRef]

22. Chia, X.; Ambrosi, A.; Sofer, Z.; Luxa, J.; Pumera, M. Catalytic and Charge Transfer Properties of Transition Metal Dichalcogenides Arising from Electrochemical Pretreatment. ACS Nano 2015, 9, 5164-5179. [CrossRef]

23. Liu, Z.; Gao, Z.; Liu, Y.; Xia, M.; Wang, R.; Li, N. Heterogeneous Nanostructure Based on 1 T-Phase MoS $_{2}$ for Enhanced Electrocatalytic Hydrogen Evolution. ACS Appl. Mater. Interfaces 2017, 9, 25291-25297. [CrossRef]

24. Ishag, A.; Sun, Y. Recent Advances in Two-Dimensional $\mathrm{MoS}_{2}$ Nanosheets for Environmental Application. Ind. Eng. Chem. Res. 2021, 60, 8007-8026. [CrossRef]

25. Jaramillo, T.F.; Jorgensen, K.P.; Bonde, J.; Nielsen, J.H.; Horch, S.; Chorkendorff, I. Identification of active edge sites for electrochemical H-2 evolution from $\mathrm{MoS}_{2}$ nanocatalysts. Science 2007, 317, 100-102. [CrossRef] [PubMed]

26. Hinnemann, B.; Moses, P.G.; Bonde, J.; Jorgensen, K.P.; Nielsen, J.H.; Horch, S.; Chorkendorff, I.; Norskov, J.K. Biornimetic hydrogen evolution: $\mathrm{MoS}_{2}$ nanoparticles as catalyst for hydrogen evolution. J. Am. Chem. Soc. 2005, 127, 5308-5309. [CrossRef] [PubMed]

27. Li, J.; Wen, Z.; Hui, Z.X.; Chen, Z.W.; Yang, C.C.; Jiang, Q. Graphene-MoS 2 vertically anchored on an MXene-derived accordionlike $\mathrm{TiO}_{2} / \mathrm{C}$ skeleton: An ultrastable HER catalyst. J. Mater. Chem. A 2020, 8, 14223-14233. [CrossRef]

28. Xiang, T.; Fang, Q.; Xie, H.; Wu, C.; Wang, C.; Zhou, Y.; Liu, D.; Chen, S.; Khalil, A.; Tao, S.; et al. Vertical 1T-MoS 2 nanosheets with expanded interlayer spacing edged on a graphene frame for high rate lithium-ion batteries. Nanoscale 2017, 9, 6975-6983. [CrossRef] [PubMed]

29. Sun, Q.; Liu, Y.; Liu, Z.; Huang, G.; Yuan, S.; Yang, G.; Wang, K.; Zhang, P.; Li, N. Symbiotic composite composed of MoS 2 and pelagic clay with enhanced disinfection efficiency. RSC Adv. 2021, 11, 9621-9627. [CrossRef] 
30. Unuabonah, E.I.; Ugwuja, C.G.; Omorogie, M.O.; Adewuyi, A.; Oladoja, N.A. Clays for Efficient Disinfection of Bacteria in Water. Appl. Clay Sci. 2018, 151, 211-223. [CrossRef]

31. Guardia, L.; Paredes, J.I.; Munuera, J.M.; Villar-Rodil, S.; Ayan-Varela, M.; Martinez-Alonso, A.; Tascon, J.M.D. Chemically Exfoliated $\mathrm{MoS}_{2}$ Nanosheets as an Efficient Catalyst for Reduction Reactions in the Aqueous Phase. ACS Appl. Mater. Interfaces 2014, 6, 21702-21710. [CrossRef] [PubMed]

32. Dai, X.; Du, K.; Li, Z.; Liu, M.; Ma, Y.; Sun, H.; Zhang, X.; Yang, Y. Co-Doped $\mathrm{MoS}_{2}$ Nanosheets with the Dominant CoMoS Phase Coated on Carbon as an Excellent Electrocatalyst for Hydrogen Evolution. ACS Appl. Mater. Interfaces 2015, 7, 27242-27253. [CrossRef] [PubMed]

33. Xie, J.; Zhang, H.; Li, S.; Wang, R.; Sun, X.; Zhou, M.; Zhou, J.; Lou, X.W.; Xie, Y. Defect-Rich MoS 2 Ultrathin Nanosheets with Additional Active Edge Sites for Enhanced Electrocatalytic Hydrogen Evolution. Adv. Mater. 2013, 25, 5807-5813. [CrossRef] [PubMed]

34. Zhang, W.; Xiao, X.; Zheng, L.; Wan, C. Fabrication of $\mathrm{TiO}_{2} / \mathrm{MoS}_{2}$ Composite Photocatalyst and Its Photocatalytic Mechanism for Degradation of Methyl Orange under Visible Light. Can. J. Chem. Eng. 2015, 93, 1594-1602. [CrossRef] 